\title{
LAS PREGUNTAS ORALES EN EL PARLAMENTO ESPAÑOL ${ }^{1}$
}

\author{
Catalina Fuentes Rodríguez \\ Universidad de Sevilla
}

\begin{abstract}
Resumen: Las preguntas orales son el único momento en el que el gobierno responde directamente a los miembros de la Cámara. Constituyen un tipo de discurso especial por su limitación de tiempo, su estructura fija, y porque en él la pregunta no siempre actúa como un requerimiento de información. El acto de habla realizado varía según el hablante y las circunstancias interactivas y apunta siempre a la acusación y la crítica. Por su parte, el gobierno recurre a la evasión a veces como modo de defensa.
\end{abstract}

Palabras clave: discurso parlamentario, preguntas orales, estructura interactiva, pragmática, evasión.

Abstract: Question time is an unique opportunity for the members of Parliament to receive a direct answer from the government. Several factors make this discourse special: time limit, fixed structure and the fact that the question seldom acts as an information request. Speech acts vary according to the speaker and interactive circumstances. They point to accusation and criticism. On the other hand, the government uses evasion as a defense device.

Keywords: parliamentary discourse, question time, interactive structure, pragmatics, evasion.

\section{INTRODUCCIÓN}

El discurso parlamentario está siendo objeto de numerosos estudios pragmáticos ya que constituye un tipo de interacción fijada, de alta formalidad, y con un uso específico del sistema lingüístico, llegando incluso a la inversión de los valores codificados (Bayley 2004, Chilton 2004, Wilson 1990, Van Dijk 2004). La ritualización y el grado elevado de enfrentamiento que constituyen sus características fundamentales hacen que los juicios sobre su nivel de cortesía (Fuentes Rodríguez 2009a y b, en prensa a y b) y la valoración de la fuerza ilocutiva de sus actos de habla tengan que ser analizados de forma particular. Esto último es

1 Este trabajo se inscribe dentro de los objetivos del proyecto de investigación FFI 2009-10515, “(Des)cortesía y medios de comunicación: estudio pragmático", financiado por el Ministerio de Ciencia e Innovación. 
más evidente en las preguntas orales, ocasión en la que los miembros de la oposición pueden interpelar directamente al gobierno.

El entorno y las condiciones de producción crean un tipo discursivo especial que merece ser estudiado detenidamente. Nuestro fin aquí, pues, es una descripción desde el Análisis del discurso de una producción textual especial y no abordada en español. Hemos analizado los Diarios de Sesiones del Parlamento Español2 ${ }^{2}$ para poder encontrar las constantes definitorias de este discurso.

\section{PREGUNTAS ORALES Y QUESTION TIME}

Los estudios sobre este género son escasos, generalmente centrados en el Parlamento británico (Wilson 1990; Harris 2001, Pérez de Ayala 2001; Ilie 2004; Chilton 2004) ${ }^{3}$ y algún estudio sobre el australiano (Raisah 2010). Son las llamadas "question time" y constituyen la parte más popular del Parlamento en estos países, lo más seguido por los periodistas, debido a su alto grado de conflicto. Es el género “adversorial” (Pérez de Ayala 2001, Chilton 2004) por excelencia, dentro del discurso parlamentario. Constituyen el único momento en el que la relación es abierta y solicitada por los miembros de la oposición, en una sesión de control del ejecutivo que muestra la cara más democrática de la política. Aunque, como todo en este ámbito, no es lo que parece.

Sin embargo, hay diferencias entre la "question time" británica y nuestras preguntas orales. En el Parlamento británico y australiano tienen una hora concreta para realizarse (de ahí el nombre), y en este caso miembros de ambos lados del congreso se levantan y presentan sus preguntas al gobierno. Estas pueden ser, como describe Raisah, "without notice", es decir, sin preparación previa, o bien "on notice”, que son la mayoría, previamente indicadas. En este último caso, el Gobierno tiene tiempo para preparar la respuesta. En España, son todas de este último tipo. Así lo expresa el reglamento del Congreso:

"Art. 188 Los escritos se presentarán con la antelación que fije la Mesa y que nunca será superior a una semana ni inferior a cuarenta y ocho horas.

2. Las preguntas se incluirán en el orden del día, dando prioridad a las presentadas por Diputados que todavía no hubieren formulado preguntas en el Pleno en el mismo período de sesiones. Sin perjuicio de este criterio, el Presidente, de acuerdo con la Junta de Portavoces, señalará el número de preguntas a incluir en el orden del día de cada sesión plenaria y el criterio de distribución entre Diputados correspondientes a cada Grupo Parlamentario". (Reglamento de la Cámara. Parlamento de España)

2 Hemos analizado los DSPA correspondientes a los meses de febrero, marzo y abril de 2010. Los que contienen preguntas orales en estas fechas son los siguientes: DSPA 140, 17-2-2010, 141- 18-2-2010, DSPA 137, 10-2-2010, DSPA 159 (28-4-2010), 156 (21-4-2010), DSPA 154 (14-4-2010), DSPA 151 (24-3-2010), DSPA 148 (17-3-2010), DSPA 145 (10-3-2010).

3 Harris 2001 e Ilie 2004 se centran en la confrontación como característica definitoria. 
En nuestro país no hay una hora establecida para hacerlas, pero sí coinciden en un día: los miércoles, día en que el gobierno acude al Parlamento a la sesión de control.

Hay otra diferencia con el Parlamento británico: en este existe la posibilidad de varios turnos de réplica (Harris 2001) y de que intervengan varios diputados del mismo grupo, apoyando su propuesta. Por ello S.Pérez de Ayala 2001 explica que el gabinete de los ministros debe preparar muchas posibles reacciones y preguntas relacionadas. En el Parlamento español hay sólo un turno de réplica.Pero en ambos casos son situaciones comunicativas con un alto riesgo para la imagen del interpelado, es decir, del Gobierno ${ }^{4}$.

En España está fijada su duración y estructura:

"188. 3. En el debate, tras la escueta formulación de la pregunta por el Diputado, contestará el Gobierno. Aquél podrá intervenir a continuación para replicar o repreguntar y, tras la nueva intervención del Gobierno, terminará el debate. Los tiempos se distribuirán por el Presidente y los intervinientes, sin que en ningún caso la tramitación de la pregunta pueda exceder de cinco minutos. Terminado el tiempo de una intervención, el Presidente automáticamente dará la palabra a quien deba intervenir a continuación o pasará a la cuestión siguiente.”

El objetivo en los dos casos es obtener una información del gobierno, requerimiento que se lleva a cabo con un alto grado de descortesía, y en tono altamente conflictivo. Esto hace replantearse la intención real de la pregunta: ¿es obtener información o atacar? Esta ambigüedad o doble objetivo explica la estructura de este tipo textual y el tipo de actos de habla que realiza 5 .

Este género debe separarse de las Interpelaciones urgentes, que, aunque puedan confluir como tipo de acto de habla, tienen una función diferente. Van dirigidas al gobierno, pero no tienen como fin preguntar u obtener necesariamente una información, sino abrir un debate, o plantear un problema. Por ello suelen estar defendidas en una intervención larga del ponente, al que responde el ministro encargado del tema. La RAE (s.v. interpelar) indica expresamente: "En el régimen parlamentario, usar la palabra para iniciar o plantear al Gobierno, y a veces a la mesa, una discusión amplia ajena a los proyectos de ley y a las proposiciones, aunque no siempre tienda a obtener explicaciones o descargos de los ministros".

\section{ESTRUCTURA TEXTUAL}

Este género discursivo tiene en español, pues, una estructura interactiva muy fijada. Se compone de dos intercambios relacionados:

4 Sobre la cortesía empleada en estas preguntas cfr. nuestro artículo en preparación "Cortesía y emotividad en las 'question time' españolas".

5 Chilton-Schäffner $(2002,31)$ considera que los actos de habla son fundamentales en el análisis del lenguaje político, pero aquí "are generally not performed by means o an explicit verbal formula" 
Intercambio 16: secuencia de inicio, formada por dos intervenciones: 1: pregunta directa, parcial o total, 2: respuesta. La primera es conocida por el interlocutor (el gobierno) ya que se presenta antes por escrito. Por tanto, la respuesta está preparada. El grado de novedad es mínimo, y su rendimiento informativo es bajo.

Intercambio 2: réplica-dúplica. Reformulación del verdadero acto de habla: ataque al ejecutivo, mediante una nueva formulación, reiteración de lo anterior, o nueva pregunta, surgida como conclusión de una interpretación de la respuesta del ministro.

Este segundo intercambio es más oral, no preparado, o no totalmente preparado. El ministro y su gabinete pueden haber previsto las posibles implicaciones. También puede que la respuesta primera sea conscientemente ambigua o indirecta para provocar la segunda pregunta.

Es decir, podemos tener las siguientes posibilidades:

Intercambio 1:

Intervención 1: preparada, conocida

Intervención 2: a) respuesta real, directa. Sincera. Preparada.

b) respuesta confusa, que no responde a lo preguntado, sino que plantea otros aspectos,

c) pretendidamente indirecta para provocar otra pregunta.

Intercambio 2:

Intervención 3: reacción ante lo anterior, ya sea:

a) preparada, verdadera cuestión: ataque o pregunta en otro sentido,

b) reacción ante el ataque que hace el ministro (esto no previsto por el que pregunta),

c) nueva cuestión, provocada por la respuesta del ministro (cae en su trampa).

Intervención 4: respuesta del representante del gobierno (defensa con/sin ataque).

En nuestro Parlamento, al ser conocida la pregunta de antemano, se puede preparar la respuesta y las posibles implicaciones, tanto por un bando como por otro.

Pero, además, a esto hay que añadirle un componente: la limitación del tiempo. Tienen que durar, como máximo, 5 minutos la pregunta completa, con las 4 intervenciones. Esto obliga a cortar, y por tanto, a ser muy rentable en la respuesta, o en la repregunta.

${ }^{6}$ Consideramos intercambio el conjunto de intervenciones de hablantes diferentes provocadas por una intervención iniciativa. Vid Fuentes 2000 y Briz-Valesco 2003. 
Al mismo tiempo, al existir sólo un turno de réplica, no da posibilidades a argumentar mucho y a enfrentarse con más extensión. El juego está más igualado, y en el fondo, tiende a primar la imagen del gobierno, ya que le permite reaccionar en un solo tiempo y ser el último que tiene la palabra, con lo que puede ganar en la lucha o impedir que se siga con el tema.

Otra característica importante, también fijada, es el tema sobre el que versa:

"Artículo 18836

1. Cuando se pretenda la respuesta oral ante el Pleno, el escrito no podrá contener más que la escueta y estricta formulación de una sola cuestión, interrogando sobre un hecho, una situación o una información, sobre si el Gobierno ha tomado o va a tomar alguna providencia en relación con un asunto, o si el Gobierno va a remitir al Congreso algún documento o a informarle acerca de algún extremo."

El tópico textual es el requerimiento de información sobre un hecho o una actuación del ejecutivo. En el primer caso es más objetiva e implica menos la imagen de los hablantes. En el segundo es más comprometido, ya que pedir información sobre una actuación realizada por el interlocutor puede alojar una crítica más o menos encubierta, con lo que la pregunta se convierte en acusación.

Esta limitación temática, como vamos a ver, no siempre se respeta. Para algunos autores, como dice Pérez de Ayala (2001,144), el fin es "to have the chance to score a political point." 7 . Para ello, el esquema textual se "manipula" para ajustarse a la verdadera intención del que habla. En otros, se llega a un enfrentamiento directo y a acusaciones fuertes.

Se prohíben, pues, las preguntas sobre un asunto de interés personal. Pero, además, los temas se limitan: es una pregunta como acto de habla, sobre "un hecho, una situación o una información", si el gobierno "ha tomado o va a tomar alguna providencia en relación con un asunto" o si va a remitir al congreso algún asunto. Sin embargo, como vamos a ver, esto no es lo que ocurre, pero para que sea admitida tiene que ser formulada de forma correcta y ajustada a derecho.

Las preguntas orales constituyen, pues, un encuentro interactivo cuyo objetivo no es realmente conseguir una respuesta, sino criticar o acusar al gobierno, o solicitar el cumplimiento de compromisos ${ }^{8}$. Para ello usan la cortesía, las formas indirectas y la acusación fuerte. Analicemos las diferentes posibilidades tanto en la pregunta como en la respuesta.

7 Questions are "part of a political battle in which party points are scored and personal or party glory pursued" (Borthwick, 1993:103). En los estudios sobre entrevistas se ha demostrado que las preguntas totales es un procedimiento para el discurso de confrontación., Vid Heritage 2002, 2003 y Emmertsen 2007.

8 Es el fin de todo texto parlamentario. Así lo afirma Ilie (2003: 31): «the end-goal of parliamentary dialogue is to affect the audience's beliefs and opinions in order to motivate to act in a certain way with regard to real-life issues. It also implies that political adversaries have to be proved wrong or at least neutralized». 


\section{LA PRIMERA PREGUNTA}

La intervención de inicio, que es la que constituye la razón de ser del discurso que se genera, debe consistir en una pregunta, que es conocida, puesto que ha sido presentada previamente por escrito. Sin embargo, podemos encontrar algunas variantes:

a) Algunas repiten literalmente la pregunta formulada:

DEL DIPUTADO DON FRANCISCO XESÚS JORQUERA CASELAS, DEL GRUPO PARLAMENTARIO MIXTO, QUE FORMULA AL SEÑOR PRESIDENTE DEL GOBIERNO: ¿PIENSA EL GOBIERNO QUE EL TRASLADO A MADRID DE LOS CENTROS RECTORES DE LAS CAJAS DE AHORRO ES LA SOLUCIÓN A LA CRISIS ECONÓMICAY A SU REPERCUSIÓN EN EL SECTOR FINANCIERO? (Número de expediente 180/000848.)

El señor JORQUERA CASELAS: Gracias, señor presidente.

Señor presidente del Gobierno, ¿piensa el Gobierno que el traslado a Madrid de los centros rectores de las cajas de ahorro es la solución a la situación de crisis económica y a su repercusión en el sector financiero? (DSPA 140, 45)

O indican que la dan por reproducida:

El señor PRESIDENTE: Última pregunta para la señora vicepresidenta. Para formularla tiene la palabra don Gerardo Conde.

El señor CONDE ROA: Gracias, señor presidente.

Señora vicepresidenta del Gobierno, doy por reproducida la pregunta en los términos en los que está formulada en el «Diario de Sesiones». (DSPA 137, 13)

b) Otros diputados la reproducen con una variante, manteniendo el mismo acto de habla, ya sea

b.1) Matizándolo, haciéndolo más explícito

- DEL DIPUTADO DON CRISTÓBAL RICARDO MONTORO ROMERO, DEL GRUPO PARLAMENTARIO POPULAR EN EL CONGRESO, QUE FORMULA A LA SEÑORA VICEPRESIDENTA SEGUNDA DEL GOBIERNOY MINISTRA DE ECONOMÍA Y HACIENDA: ¿POR QUÉ NO INTRODUJO EL GOBIERNO SU RECORTE DE GASTOS EN EL PRESUPUESTO QUE SE APROBÓ HACE ALGO MÁS DE UN MES? (Número de expediente 180/000833.) (...)

El señor MONTORO ROMERO: Gracias.

Señora vicepresidenta segunda, ¿̇no conocía el Gobierno la previsión del déficit público seis semanas antes - es decir, cuando estábamos aprobando en esta Cámara los presupuestos-, de forma que se podía haber ahorrado la propuesta la recorte de gasto que ha hecho a finales de enero? (DSPA 137,10) 
En ambas formulaciones la interrogativa no expresa realmente una pregunta sino que deja inferir una acusación”. Ha cambiado de una parcial: “¿por qué no introdujo...?” a una total negativa: “¿no conocía...?”, que orienta hacia una afirmación.

En esta otra comienza preguntando por la responsabilidad de la Ministra para luego formularla de otro modo:

DE LA DIPUTADA DOÑA MARÍA SORAYA SÁENZ DE SANTAMARÍA ANTÓN, DEL GRUPO PARLAMENTARIO POPULAR EN EL CONGRESO, QUE FORMULA A LA SEÑORA VICEPRESIDENTA PRIMERA DEL GOBIERNO, MINISTRA DE LA PRESIDENCIA Y PORTAVOZ DEL GOBIERNO: ¿QUÉ GRADO DE RESPONSABILIDAD TIENE LA VICEPRESIDENTA EN LA ABSOLUTA FALTA DE RIGOR DEL GOBIERNO DE JOSÉ LUIS RODRÍGUEZ ZAPATERO? (Número de expediente 180/000832.)

Su formulación es:

Y yo le pregunto ¿cree usted, señoría, que un asunto tan serio como las pensiones de los españoles puede abordarse con tan poco rigor? (DSPA 137, 9).

Pasa de una pregunta parcial en la que se piden responsabilidades a pedir formalmente una opinión, aunque en realidad es una acusación fuerte, pero expresada de forma indirecta. Los elementos evaluativos ("un asunto tan serio") y los intensificadores ("absoluta ${ }^{10}$ falta de rigor") aclaran la fuerza argumentativa y el grado de conflicto presente, y cambian el acto de habla. Orientan la inferencia.

b.2.) Haciéndolo preceder de un marco argumentativo. En este caso puede alterar la fuerza argumentativa de la pregunta, orientarlo en cierto sentido, o incluso insinuar una amenaza velada, con lo cual estaríamos ante un cambio de acto de habla (tipo c). Así el siguiente caso en el que el preámbulo indica presupuestos que obligan a una determinada respuesta.

- DEL DIPUTADO DON GUILLERMO MARISCAL ANAYA, DEL GRUPO PARLAMENTARIO POPULAR EN EL CONGRESO, QUE FORMULA AL SEÑOR VICEPRESIDENTE TERCERO DEL GOBIERNO Y MINISTRO DE POLÍTICA TERRITORIAL: ¿PUEDE ACLARAR EL VICEPRESIDENTE TERCERO Y MINISTRO DE POLÍTICA TERRITORIAL LOS COMPROMISOS PRESUPUESTARIOS CONCRETOS QUE SUPONE LA ESTRATEGIA

9 Burguera (2010) en su tesis defiende que el uso de las interrogativas retóricas en el discurso parlamentario en general tiene un fin argumentativo-lesivo, constituye un mecanismo indirecto de descortesía, cuyas funciones pragmáticas son la queja, el reproche, el desafío y la insinuaciónconjetura. Cfr. asimismo el magnífico trabajo de Ilie (1994).

10 Cfr. Fuentes 2006 y 2009c. 


\begin{abstract}
INTEGRAL PARA LA COMUNIDAD AUTÓNOMA DE CANARIAS? (Número de expediente 180/000854.)

El señor PRESIDENTE: Preguntas para el señor vicepresidente tercero del Gobierno. Para formularla tiene la palabra don Guillermo Mariscal.

El señor MARISCAL ANAYA: Le recuerdo, señor vicepresidente, que usted y su Gobierno adquirieron un compromiso con Canarias el 9 de octubre para invertir 25.000 milllones de euros en los próximos diez años, 10.000 de los cuales serían en los primeros cuatro. (La señora vicepresidenta, Cunillera i Mestres, ocupa la Presidencia.) Le recuerdo, además, que el Gobierno no puede firmar cheques sin fondos, señor vicepresidente, porque si no lo que están haciendo ustedes es un tomadura de pelo o, como bien decía recientemente Paulino Rivero, ZP con el Plan Canarias buscaba un titular. Por eso es por lo que le pregunto: ¿Puede aclarar cuáles son las inversiones concretas de la estrategia integral para Canarias? Porque como usted sabrá, señor vicepresidente, lo que no está en el presupuesto no existe, no es de este mundo. Gracias. (Aplausos.) (DSPA 140, 50).
\end{abstract}

La pregunta es cortés (¿̈puede aclarar...?) pero la justificación (porque...) y la presencia de le recuerdo activando informaciones presupuestos, presionan al ministro para que no haga una declaración sin compromiso, lo obligan. Como usted sabrá convierte al receptor en garante de lo dicho, se apoya en él. En el fondo no es una propuesta, es un acorralamiento, y una acusación de que no cumple lo pactado.

b.3.) Orientando la respuesta con argumentos. Así, de forma parecida, el Sr. Llamazares apoya su pregunta con argumentos antiorientados que la convierten en una acusación indirecta clara: hay parte de la sociedad que se opone a la política del gobierno. La pregunta pasa de $\dot{\leftrightarrow}$ mantiene el gobierno? a ¿̇piensa retirar?

- DEL DIPUTADO DON GASPAR LLAMAZARES TRIGO, DEL GRUPO PARLAMENTARIO DE ESQUERRA REPUBLICANA-IZQUIERDA UNIDA-INICIATIVA PER CATALUNYA VERDS, QUE FORMULA AL SEÑOR PRESIDENTE DEL GOBIERNO: ¿MANTIENE EL GOBIERNO SU PROPUESTA DE RETRASAR LA EDAD DE JUBILACIÓN A LOS 67 AÑOS? (Número de expediente 180/000849.)

El señor PRESIDENTE: Nueva pregunta para el señor presidente. Para formularla tiene la palabra don Gaspar Llamazares.

E1 señor LLAMAZARES TRIGO: Gracias, señor presidente.

Señor presidente del Gobierno, cpiensa usted retirar la propuesta de retrasar la edad de jubilación, teniendo en cuenta el rechazo unánime de la población española y teniendo en cuenta también el rechazo de las organizaciones sindicales y de la inmensa mayoría de los grupos parlamentarios de esta Cámara? (DSPA 140, 47) 
En el caso siguiente la conminación es mucho más fuerte, y pasa casi a una obligación. El diputado exige una respuesta directa. El preámbulo pretende dar fuerza a su intención argumentativa:

- DEL DIPUTADO DON IGNACIO GIL LÁZARO, DEL GRUPO PARLAMENTARIO POPULAR EN EL CONGRESO, QUE FORMULA AL SEÑOR MINISTRO DEL INTERIOR: ¿HA PROPORCIONADO SIEMPRE EL MINISTRO DEL INTERIOR INFORMACIÓN VERAZ A ESTA CÁMARA EN RELACIÓN CON EL LLAMADO «CASO FAISÁN»? (Número de expediente 180/000860.) La señora VICEPRESIDENTA (Cunillera i Mestres):

Pregunta del diputado Gil Lázaro.

El señor GIL LÁZARO: Muchas gracias, señora presidenta.

Señor ministro del Interior, responda tan solo sí o no. ¿Ha proporcionado siempre información veraz a esta Cámara en relación con el llamado caso Faisán? (DSPA 140, 54)

La pregunta se convierte en una exigencia.

c) Hay casos en que el cambio de acto de habla se opera de forma directa, no a través de la implicatura. Se pasa de lo establecido, el requerimiento de información, a una acusación directa, se olvida la pregunta y se pasa al ataque. Un caso muy claro es el siguiente:

- DE LA DIPUTADA DOÑA MARÍA SORAYA SÁENZ DE SANTAMARÍA ANTÓN, DEL GRUPO PARLAMENTARIO POPULAR EN EL CONGRESO, QUE FORMULA A LA SEÑORA VICEPRESIDENTA PRIMERA DEL GOBIERNO Y MINISTRA DE LA PRESIDENCIA: ¿CÓMO ENTIENDE LA VICEPRESIDENTA PRIMERA LAS RELACIONES ENTRE EL PODER EJECUTIVO Y EL PODER LEGISLATIVO? (Número de expediente 180/000853.)

El señor PRESIDENTE: Se acabaron las preguntas para el señor presidente del Gobierno.

Pregunta para la señora vicepresidenta primera. Para formularla tiene la palabra doña Soraya Sáenz de Santamaría.

La señora SÁENZ DE SANTAMARÍA ANTÓN:

Muchas gracias, presidente.

Voy a aprovechar, dado que estamos en racha con el presidente del Gobierno, para ver si hoy obtengo una respuesta sobre una cosa que le llevo pidiendo desde hace tiempo a la señora De la Vega. Un ejemplo muy claro de cómo entiende la señora De la Vega sus relaciones con esta Cámara, sus relaciones con el Poder Legislativo, es un caso conocido como el caso Faisán.

El pasado 28 de octubre usted, la vicepresidenta primera del Gobierno, no respondió a una pregunta que yo le hice en esta Cámara, en esta misma casa, alegando incompetencia. El ministro Rubalcaba, desde entonces, ha venido combinando el escapismo parlamentario con la falsedad. Y el pasado miércoles, 
precisamente a preguntas de mi grupo parlamentario, el ministro de Justicia despachaba el tema diciendo que son solo rumores. No sé si necesitará que le recuerde lo que dijo la Audiencia Nacional el pasado lunes. La Audiencia Nacional dijo que lo que ustedes llaman rumores es un caso de gravedad, y cito textualmente, sin precedentes en la historia de la lucha contra el terrorismo en España. Por eso, señoría, creo que hoy usted debe dar una respuesta en esta Cámara. Y debe darla porque la policía no puede seguir siendo comprometida por ustedes con su silencio. Y debe darla porque no se puede poner en entredicho el prestigio del Estado de derecho, que es el principal instrumento de (49) algo que creo que compartimos todos, que debe ser una lucha unánime y sin cuartel contra el terrorismo. Yo le pregunto porque estoy en el ejercicio de mi obligación democrática como representante del Poder Legislativo de someter a control las acciones del Ejecutivo y especialmente velar por que el Ejecutivo cumpla siempre, siempre la legalidad en el ejercicio de sus funciones. Yo estoy cumpliendo con mi obligación haciéndole esta pregunta. Espero que usted hoy cumpla con la suya. Muchas gracias. (Aplausos.) (DSPA 140, 48-9).

La sra. Sáenz de Santamaría presenta la pregunta (¿cómo entiende la Sra. Vicepresidenta las relaciones entre el poder ejecutivo y el legislativo?) en el marco de una secuencia informativa con la que abre su intervención: voy a aprovechar... Un ejemplo muy claro de cómo entiende... A esto sigue una narración de hechos que le sirven para acusar a diferentes miembros del gobierno, y una conminación a responder en forma de obligación ("creo que hoy usted debe dar una respuesta en esta Cámara... Espero que hoy cumpla con la suya”). La pregunta es un pretexto para acusar de no responder.

En el caso siguiente, la pregunta del Sr. González Pons se convierte en una acusación y mandato explícito:

- DEL DIPUTADO DON ESTEBAN GONZÁLEZ PONS, DEL GRUPO PARLAMENTARIO POPULAR EN EL CONGRESO, QUE FORMULA A LA SEÑORA MINISTRA DE MEDIO AMBIENTE, Y MEDIO RURAL Y MARINO: ¿VA A ADOPTAR EL MINISTERIO DE MEDIO AMBIENTE, Y MEDIO RURAL Y MARINO LAS MEDIDAS LEGALES OPORTUNAS PARA MANTENER LOS ESTABLECIMIENTOS HOSTELEROS DE LAS PLAYAS ESPAÑOLAS? (Número de expediente 180/000999.)

La señora VICEPRESIDENTA: Pregunta dirigida a la señora ministra de Medio Ambiente, y Medio Rural y Marino, que formula el diputado señor González Pons.

El señor GONZÁLEZ PONS: Asisten a la sesión los representantes de la hostelería y de los trabajadores de hostelería de Valencia. Señora ministra, si usted piensa que los restaurantes, terrazas y chiringuitos de las playas españolas no caben en la Ley de Costas, cambie la Ley de Costas, pero no destruya 45.000 puestos de trabajo a lo largo de toda España, 5.000 solo en la provincia de Valencia. (Rumores.) 
La señora VICEPRESIDENTA: ¡ Por favor!

El señor GONZÁLEZ PONS: porque España en este momento no está para que un miembro de su Gobierno, con una decisión política, contribuya aún más a la destrucción de empleo. (Aplausos.) (DSPA 159, 10)

La pregunta se ha convertido en una petición ("cambie pero no destruya") y una acusación ("un miembro de su gobierno destruye empleo", información presupuesta en la oración subordinada final). No hay ninguna forma interrogativa en la formulación oral, sino que se realiza explícitamente el nuevo acto de habla.

En otros casos está claramente orientada la pregunta hacia la acusación. Así ocurre con formas totales, en negativa:

- DEL DIPUTADO DON VICENTE MARTÍNEZ-PUJALTE LÓPEZ, DEL GRUPO PARLAMENTARIOPOPULAR EN EL CONGRESO, QUE FORMULA A LA SEÑORA VICEPRESIDENTA SEGUNDA DEL GOBIERNO Y MINISTRA DE ECONOMÍA Y HACIENDA: ¿CONSIDERA EL GOBIERNO QUE EL AUMENTO DE LA DEUDA PÚBLICA AGRAVA LA FALTA DE CRÉDITO PARA FAMILIAS Y EMPRESAS ESPAÑOLAS? (Número de expediente 180/000834.)

El señor PRESIDENTE: Segunda pregunta para la señora vicepresidenta. Para formularla tiene la palabra don Vicente Martínez-Pujalte.

El señor MARTÍNEZ-PUJALTE LÓPEZ: Muchas gracias, señor presidente.

Señora vicepresidenta, no quiero participar de ninguna teoría conspirativa ni estoy bajo los influjos de conjunciones planetarias, simplemente estoy preocupado porque la situación de la deuda pública española, que se ha multiplicado con ustedes, que en dos años ha crecido desmesuradamente, está poniendo en peligro el Estado del bienestar y está poniendo en peligro el acceso al crédito de familias y empresas. Señora vicepresidenta, métase con quien quiera, pero ¿no cree que es hora de ir reduciendo la deuda pública y de hacer algo para que las familias y las empresas tengan acceso al crédito? (DSPA 137,12)

La pregunta escrita sigue la fórmula tradicional: “¿considera el gobierno...?” Parece una pregunta real. Luego, cuando se expone se muestra la intención del hablante claramente con ese "es hora de ir... y hacer algo...” El “'no cree?” es una afirmación tajante, y una reconvención, aunque cortés.

Esta inversión del valor ilocutivo que sufren estos enunciados se debe a su función discursiva. Hay que entenderlo dentro del modelo tipológico, dentro de su superestructura, y esta dentro de una visión contextual, interactiva y social (Fuentes 2000). Es decir, dentro del género parlamentario, la única posibilidad de tener un diálogo (o remedo del mismo) sobre un tema concreto es este apartado de preguntas orales. Es la sesión de control al gobierno. $\mathrm{Y}$ a veces el control supone la crítica, la acusación, el rechazo, y no necesariamente la petición de 
información. Pero el sistema de funcionamiento de la Cámara sólo permite los requerimientos de información, por lo cual el diputado recurre a ello en la primera intervención para en el segundo intercambio mostrar realmente su intención. Esta primera intervención, pues, adquiere una función macroestructural, de abrir el intercambio y facilitar la creación del texto.

Estas preguntas aparecen bajo la forma de interrogativas totales o parciales.

-Totales: Presuponen respuesta sí /no. Las formas lingüísticas utilizadas son

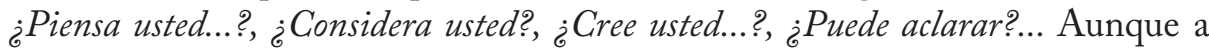
veces se reproducen de forma indirecta. Por ejemplo, en la del Sr. Cosidó la pregunta era una parcial: "¿Cuál es la implicación del Secretario de Estado de Seguridad en el caso del chivatazo a ETA?” Y cuando la formula el diputado, empieza con un preámbulo al que sigue la presentación de forma indirecta: "Mi pregunta, señor ministro, es si en esas conversaciones se habló del denominado caso Faisán”. Pero la implicatura en estos casos apunta a otro acto de habla: la crítica.

En estos enunciados se establece una pregunta como acto ritual de inicio para abrir el intercambio y seguir lo establecido por las normas de funcionamiento de la cámara. Son constricciones de tipo superestructural y social. Por tanto, estos verbos de opinión: considera, cree... son formas de cortesía, atenuativos. Cuando aparece ipuede aclarar...? no es una pregunta realmente, sino una petición cortés: "acláreme, por favor..." (es la pregunta del Sr. Mariscal al Vicerpresidente tercero del gobierno).

En algunos casos la implicatura es clara hacia la acusación, en este caso, de mentir:

E1 señor GIL LÁZARO: Muchas gracias, señora presidenta.

Señor ministro del Interior, responda tan solo sí o no. ¿Ha proporcionado siempre información veraz a esta Cámara en relación con el llamado caso Faisán?

-Interrogativas parciales: ¿̇cómo entiende..., ¿̇Por qué...? O ¿ Cuál es la implicación...? En estas se presupone el contenido afirmado: si se pregunta por la causa, o el grado de implicación, esta se da por asertada, y se presupone.

La señora BARKOS BERRUEZO: Gracias, señora presidenta.

Señor ministro, ¿qué datos maneja el Gobierno sobre la edad real de jubilación para proponer ahora la subida en dos años de la edad oficial de jubilación? (DSPA 137, 18).

Sr. Montoro: (...) ¿POR QUÉ NO INTRODUJO EL GOBIERNO SU RECORTE DE GASTOS EN EL PRESUPUESTO QUE SE APROBÓ HACE ALGO MÁS DE UN MES? (Número de expediente 180/000833.) (...) (DSPA 137, 10). 
$\mathrm{Su}$ acto de habla no tiene como fin buscar una información que no se tiene, sino intentar provocar una información para que sea oída por otros. Se trata de provocar, no de preguntar. La pregunta estaría más cerca de otros actos de habla. Muchas veces su interés radica en las inferencias que provoca en el receptor. Este es el objetivo real del diputado que pregunta. Esto provoca la segunda intervención del interpelador, a la que responde el interpelado en un último turno de dúplica.

La limitación de espacio también es importante, y eso obliga a ciertas formas directas, y a cambiar el tono del discurso, más cerca del enfrentamiento directo conversacional. En general, en este género de preguntas se huye de la verborrea fácil. $\mathrm{Al}$ menos, no se usa de forma constante.

\section{INTERVENCIÓN DE RESPUESTA: LA EVASIÓN}

La segunda intervención, de respuesta del gobierno, debe ser concreta, pero aquí encontramos desde una respuesta directa a consideraciones generales hasta repetir que ya se ha dicho y obligar a que el otro infiera la respuesta.

A) Respuesta: directa: sí, no

Sr. Cosidó: (...) Mi pregunta, señor ministro, es si en esas conversaciones se habló del denominado caso Faisán. (...)

El señor MINISTRO DEL INTERIOR (Pérez Rubalcaba): Muchas gracias, señora presidenta.

No, señor Cosidó. (DSPA 140, 53)

En otras ocasiones aparece un adverbio modal, que actúa como respuesta asertiva, intensificada.

El señor FERNÁNDEZ DE MESA DÍAZ DEL RÍO: Gracias, señora presidenta.

Señora ministra de Defensa, ¿considera que se están cumpliendo las previsiones de despliegue de la protección de las tropas en escenarios de guerra?(...)

La señora MINISTRA DE DEFENSA (Chacón Piqueras): Escrupulosamente, señoría. (Aplausos.) (DSPA 140, 52).

O se responde con los datos concretos requeridos:

Sr. Mariscal: (...)Por eso es por lo que le pregunto: ¿Puede aclarar cuáles son las inversiones concretas de la estrategia integral para Canarias? Porque como usted sabrá, señor vicepresidente, lo que no está en el presupuesto no existe, no es de este mundo. Gracias. (Aplausos.) (...)

El señor VICEPRESIDENTE TERCERO DEL GOBIERNO Y MINISTRO DE POLÍTICA TERRITORIAL (Chaves González): Muchas gracias, señora presidenta. 
Señor Mariscal, el Gobierno de España va a invertir en Canarias 25.000 millones de euros durante los próximos diez años. De estos 25.000 mil millones, 2.229 se invertirán con cargo a los Presupuestos Generales del Estado de la siguiente forma, para que usted tome nota, señor Mariscal: 574 millones en inversión directa - capítulo 6-; 811 millones en transferencia de capital a empresas y administraciones — capítulo 7-; 752 millones en convenios y subvenciones — capítulo 4-y 92 millones en operaciones financieras — capítulo 8- Como ve, señor Mariscal, esto es algo más que un compromiso presupuestario; es una realidad presupuestaria recogida en los Presupuestos Generales del Estado para el año 2010. (DSPA 140, 50).

B) Respuesta parcial, o indirecta: el interpelado está en desacuerdo con la pregunta. Indica que está mal informado, es incorrecto.

C) Le respondí ya.

En la siguiente respuesta del Presidente del Gobierno a Gaspar Llamazares encontramos estos dos últimos casos: empieza indicándole que ya ha hablado de ese tema, para, a continuación, establecer un discurso en el que intenta justificar su negativa, señalando que no es su obligación ni tiene capacidad de decisión en ese tema:

E1 señor LLAMAZARES TRIGO: Gracias, señor presidente.

Señor presidente del Gobierno, ¿piensa usted retirar la propuesta de retrasar la edad de jubilación, teniendo en cuenta el rechazo unánime de la población española y teniendo en cuenta también el rechazo de las organizaciones sindicales y de la inmensa mayoría de los grupos parlamentarios de esta Cámara? (...) El señor PRESIDENTE DEL GOBIERNO (Rodríguez Zapatero): Gracias, señor presidente.

Señor Llamazares, antes ya me he referido a esta cuestión. El Gobierno cumple con un mandato, con una petición de la Cámara. Hace una propuesta, que incluye la prolongación de la edad de jubilación, sobre el futuro del sistema de pensiones para tener un debate de país sereno, porque lo podemos tener sereno, no tenemos urgencia en cuanto a la solvencia y la solidez del sistema de Seguridad Social. Ese debate es necesario. No hacerlo es irresponsable. No decir a la ciudadanía que dentro de veinticinco años podemos tener problemas en la Seguridad Social por el proceso de envejecimiento de la población y que queremos mantener buenas pensiones, cada día mejores pensiones para todos los que lleguen a la edad de jubilación sería irresponsable. Vamos a hacerlo. Nuestra propuesta, como no puede ser de otra manera, es para el consenso lo he dicho- en el Pacto de Toledo con los partidos y con los agentes sociales. Estamos abiertos a otras propuestas, a debatirlas, a ponerlas encima de la mesa y a buscar la mejor desde nuestros principios, desde nuestro análisis y desde nuestra posición. Por eso le decía que vaya a la mesa, explique y razone propuestas alternativas. Nosotros vamos a escuchar, y como considero que el interés nacional y la Seguridad Social y el sistema de pensiones están por encima de cualquier otra circunstancia, mi deseo y mi compromiso fundamental es un 
gran acuerdo nacional sobre el futuro del sistema de pensiones. Esa es la posición del Gobierno. Gracias. (Aplausos.) (DSPA 140, 47).

También aparecen formas indirectas de eludir la respuesta, las que Rasiah llama formas de evasión ${ }^{11}$, siguiendo a Dillon (1990). Para éste (Dillon 1990: 154) la evasión es "routine strategy for responding to a question without answering it". Es una conducta frecuente en los políticos (Wilson, 1990; Harris, 1991; Bull and Mayer, 1993; Bull, 1994, 2003). Rasiah (2010, 667) establece una tipología de las respuestas evasivas dentro de una clasificación completa de las preguntas:

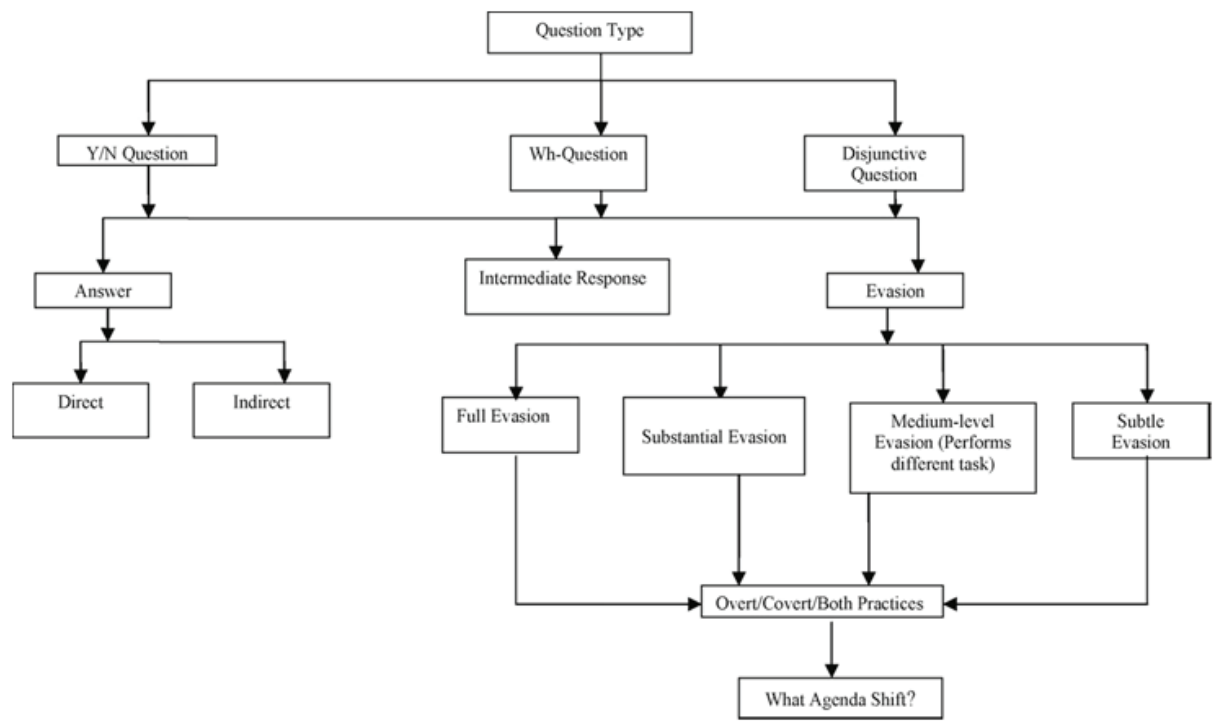

Según Rasiah, en ellas el hablante puede:

1) Responder: de forma directa / indirecta. A veces se da de forma indirecta o implícita: ya le respondí ayer.

2) Utilizar las que ella llama respuestas "intermediate", es decir, aquellas que se hacen a preguntas que envuelven una presuposición falsa, hipotética, o con la que no se está de acuerdo. Pueden ser estas respuestas: a) presuposición en la pregunta, b) la pregunta es hipotética, el asunto no se ha producido, c) no tiene la respuesta cuando le piden un dato concreto, d) motivos de seguridad.

3) Las respuestas evasivas: a) completa: cuando no responde, b) sustancial: cambia a un tema diferente, c) nivel medio: dentro del tema, habla de otro aspecto, generaliza, d) sutil: se cambian los términos de la pregunta de forma sutil.

11 "MPs are likely to contain a built-in hostility which often leads to evasion" (Rasiah 2010, 666). 
Las formas de expresión de la evasión pueden ser abiertas o encubiertas: Abiertas: a) pedir permiso para cambiar el tema: "permítame decirle que..., hablar de...”, b) minimizar la divergencia, c) justificar el cambio.

Encubiertas: a) repetir pronombres o palabras, pero no responder, b) "operar" sobre la pregunta: reformulándola, especificándola en otro sentido, etc., c) otros medios: repetición, uso de palabras similares, uso de términos vagos...

Por último trata las "agenda shifts", casos de no respuesta, cambios en la intención comunicativa, cuyos medios, según Pérez de Ayala (2001, 673), son los siguientes, adaptados de Bull-Mayer (1993):

i. Attacks the questioner

ii. Makes political points

a. External attack-attacks opposition or other rival groups

b. Talks up one's own side

c. Presents policy

iii. States or implies that the question has already been answered.

Casos de evasión encontramos en la siguiente respuesta del ministro Rubalcaba:

E1 señor GIL LÁZARO: Muchas gracias, señora presidenta.

Señor ministro del Interior, responda tan solo sí o no. ¿Ha proporcionado siempre información veraz a esta Cámara en relación con el llamado caso Faisán? (...)

El señor MINISTRO DEL INTERIOR (Pérez Rubalcaba): He contestado siempre a sus preguntas, señor Gil Lázaro. (DSPA 140, 54)

La respuesta es ambigua, ya que responde a la presuposición de la pregunta, no a la pregunta en sí, y mucho menos a destruir la inferencia que pudiera deducirse de ella. Es una forma de responder sin mentir.

Hay que tener en cuenta que en los casos de terrorismo, como es el que aquí nos ocupa, el ministro del Interior puede estar hasta cierto punto legitimado a no dar cuenta exacta y pormenorizada de todas las informaciones para no poner en riesgo operaciones policiales. Pero puede entenderse como una ocultación, una mentira.

\section{SEGUNDO INTERCAMBIO}

Tratamos ahora en conjunto las dos intervenciones del segundo intercambio ya que en ellos se produce un cambio del acto de habla a la verdadera intención del hablante. Está formado por dos intervenciones:

Intervención 3 (hablante 1): réplica- ataque, se muestra el verdadero acto de habla. Acusación, crítica, reivindicación 
Intervención 4 (hablante 2): dúplica- contrarréplica:

a) contraataque al otro partido: acusaciones, comparaciones con él

b) suspensión de la pregunta.

En ellas aparecen frecuentemente marcas de subjetividad para acusaciones y reacciones, en algunos casos indirección y formas de cortesía.

Veamos algún caso. En el primero, del que ya hemos reproducido algún fragmento, el sr. Mariscal pregunta por los compromisos sobre Canarias. Responde el Vicepresidente con datos y a ello sigue la crítica a la gestión (vid lo anterior supra):

La señora VICEPRESIDENTA (Cunillera i Mestres):

Gracias, señor vicepresidente. Señor Mariscal.

El señor MARISCAL ANAYA: Señor vicepresidente, Canarias vive actualmente un drama social: 26,9 por ciento de paro, 118.000 personas que no perciben ni subsidio ni desempleo; hay más personas cobrando subsidio que paro en Canarias ahora mismo. Evidentemente necesitamos una estrategia concreta para Canarias por parte de la Administración General del Estado para reactivar la actividad económica y frenar el elevado número de desempleados, pero el Plan Canarias no contempla ninguna novedad, no hay nada nuevo, ninguna nueva medida, apenas 100 millones de euros más para el año que viene. Han convertido ustedes el Plan Canarias en un sumatorio de medidas que ya estaban contempladas y previstas con anterioridad a la celebración del Consejo de Ministros, señor vicepresidente. Si es que es una desfachatez, si es que ustedes han incluido el Fondo de Compensación Interterritorial también en este proyecto e incluso el Fondo de Empleo Local también lo han incluido. Un sumatorio, en definitiva. Señor vicepresidente, lo que usted está haciendo aquí es el modelo clásico de la política que tiene Zapatero. Es decir, anuncio, rueda de prensa, grandes expectaciones y frustración. Continuamente la misma estrategia. No tienen ninguna credibilidad, y ya no lo digo yo sino que lo dice el presidente del Gobierno de Canarias que apoyó estos Presupuestos Generales del Estado junto con ustedes.

Recientemente en una entrevista decía que ve al Gobierno excesivamente tibio y con falta de convicción en aquellas reformas estructurales que son imprescindibles, señor vicepresidente. Tengo el convencimiento moral de que usted sabía que no se iba a cumplir el Plan Canarias, como tampoco han cumplido la inversión media por habitante que exige el Régimen Económico y Fiscal de $\mathrm{Ca}$ narias, que es la media de toda España: 238 menos por canario que el resto de la media del territorio nacional. Los diputados canarios le exigimos que adelante y active ya las medidas que prevé ese plan, seleccione cuáles, diga cuándo y cuánto va a invertir. Es su obligación y el compromiso que ustedes adquirieron el 9 de octubre con todos los canarios.

Muchas gracias. (Aplausos.) (DSPA 140, 50).

El Sr. Mariscal declara que no se les promete nada nuevo, y lo valora con calificativos como desfachatez, con un modificador realizante (Fuentes-Alcaide 
2002): si es que..., que le da más fuerza, y además lo repite. Llega a la valoración, a lo emocional, a la acusación fuerte, apoyada en la descalificación: "Si es que es una desfachatez". El final lleva a "le exigimos", postura de fuerza. Ante esto el vicepresidente reacciona contraargumentando y atacando también, aunque de forma cortés: al principio le ruega que se repase los Presupuestos Generales del Estado, para atacar personalmente después: “¿Por qué se opone?”, de forma repetitiva.

El señor VICEPRESIDENTE TERCERO DEL GOBIERNO Y MINISTRO DE POLÍTICA TERRITORIAL (Chaves González): Señor Mariscal, le ruego que se repase usted los Presupuestos Generales del Estado para el año 2010. Léaselo y verá todos los compromisos del Gobierno en relación con Canarias. Hay un compromiso muy claro de invertir más que nunca en Canarias pero ustedes, como siempre, a la contra. Yo le pregunto a usted: ¿Por qué se opone y quiere descalificar que el Gobierno de España quiera invertir 25.000 millones de euros en Canarias? ¿Por qué se opone? ¿Por qué se opone, señor Mariscal? ¿Por qué se opone a que el Gobierno de España adquiera el compromiso de establecer un horizonte de seguridad económica para el Archipiélago? Se lo puedo decir con toda claridad, señor Mariscal: ustedes no soportan que el Gobierno socialista invierta en Canarias el doble de lo que invirtió el Gobierno del Partido Popular durante su etapa. (Aplausos.) Eso es lo que les ocurre a ustedes..No soportan que el Gobierno de España vaya a mantener el esfuerzo inversor durante diez años, quieren evitar que se ponga de manifiesto que este Gobierno hace por Canarias lo que ustedes no fueron capaces de hacer durante su etapa de Gobierno, señor Mariscal. Eso es lo que les pasa. (Aplausos.) (DSPA, 140, 51)

Las preguntas retóricas, reiteradas, le dan más fuerza a su acto de habla, y a lo que afirma la pregunta: ustedes se oponen... Las preguntas implican: "ustedes se oponen y no hay una razón "confesable" o políticamente correcta, porque no deberían oponerse a las mejoras en su comunidad”. A esto sigue: se lo puedo decir con toda claridad. Chaves verbaliza los dos actos de habla, el de pregunta y el de declaración, con un modificador realizante: con toda claridad. Por tanto, es sincero, claro.

En el siguiente hay una respuesta directa a la primera cuestión del sr. Cosidó (lo vimos más arriba: Rubalcaba responde "no"), pero como la intención de la pregunta no era esa, ya que se presuponía la respuesta negativa del ministro, sigue la crítica y la acusación al gobierno. El ministro se defiende y la devuelve:

El señor COSIDÓ GUTIÉRREZ: Muchas gracias, señor ministro por la respuesta. La Audiencia Nacional decidió hace dos días que se va a seguir investigando este caso en una resolución que seguro que le satisface tanto como a mí, por tanto aquí no hemos venido a dirimir posibles responsabilidades penales sino algunas responsabilidades políticas. Es muy normal que un secretario 
de Estado de Seguridad y un director general de la Policía hablen frecuentemente, pero hay dos anomalías importantes en estas conversaciones que exigen una respuesta por su parte. La primera anomalía es que no es nada normal, no ha ocurrido nunca en ningún país del mundo, que un director general de la Policía sea imputado por un delito de colaboración con banda armada; y en segundo lugar tampoco es normal, señor ministro, que cuando un director general de la Policía y un secretario de Estado de Seguridad hablan lo hagan con el mismo teléfono que utilizaban los terroristas cuando hablaban con el Gobierno, en la negociación con ETA. Por tanto, señor ministro, usted es un Houdini parlamentario pero yo creo que hay muchos españoles hoy esperando que usted dé una respuesta convincente, $\mathrm{y}$ si usted no puede o no quiere dar esa respuesta convincente a esta situación absolutamente anómala creo que lo menos que tiene que hacer es cesar al secretario de Estado porque lo que España no puede permitirse es tener a un secretario de Estado de Seguridad bajo sospecha.

Señor ministro, la última vez que usted defendió a un miembro del Gobierno de otro caso en su anterior etapa, esa persona terminó en la cárcel. Tiene por tanto un déficit importante de credibilidad en la defensa que sin duda creo que hará del secretario de Estado. Para derrotar al terrorismo, señor ministro, no valen ni el atajo de la guerra sucia ni el atajo de la paz sucia, lo que vale es la firmeza del Estado de derecho, nuestras convicciones democráticas y la defensa de las víctimas - por cierto, le eché de menos en el congreso de Salamanca-. Con la misma firmeza que le estamos apoyando en su política antiterrorista, le exigimos que asuma sus responsabilidades en este caso que jamás debió ocurrir. (Aplausos.) (DSPA 140, 53).

Lo acusa directamente de Houdini parlamentario, de estar bajo sospecha, de no tener credibilidad, y hace presuponer que practica la "paz sucia". Incluso el paréntesis "por cierto..." es capcioso, deja entrever que no está con las víctimas. De nuevo la acusación indirecta, velada, a través de las informaciones. Rubalcaba responde:

Señor Cosidó, creo que he contestado catorce veces a preguntas parlamentarias de usted y de su compañero Gil Lázaro sobre este tema. Es más creo que en los últimos meses, desde septiembre, solo he contestado preguntas parlamentarias de este tema, de usted y del señor Gil Lázaro. Por tanto Houdini parlamentario, cero; es más, el martes estuve en el Senado, cero. Le podría decir que me inspira tanto terror su insidiosa intervención, que es la de siempre, que me busqué un cambio del orden del día del Parlamento de Estrasburgo para no estar aquí, pero... no es verdad, no es así. Le diré una vez más y lo diré en la Cámara que hay un proceso de investigación judicial que yo respeto y el Gobierno respeta y en el que ustedes están personados con toda seguridad para ayudar a que se acaben las cosas, sin ninguna intencionalidad, estoy completamente seguro--- el gobierno respeta, lo diré..., estoy seguro... con toda seguridad.. para ayudar... Le diré también que los implicados en esa operación están todos procesados - fueron detenidos y procesados-, y eso tiene que quedar muy claro porque eso sí que afecta a la lucha antiterrorista. Finalmente le diré algo 
más: que el director general de la Policía y el secretario de Estado de Seguridad hablen es lo normal, todos los días, por la mañana, por la tarde y por la noche. ¿Qué tiene eso de raro? No tiene nada de raro, salvo que alguien tenga en la cabeza insidias políticas, que es lo que usted hace una y otra vez - en esta Cámara desde hace algunos meses, contra los policías, contra los jueces, contra los fiscales y ahora contra los responsables del Ministerio del Interior; insidias políticas, señor Cosidó, esa es su especialidad en esta Cámara. (Aplausos.) (DSPA 140,54)

Le devuelve sus acusaciones, lo acusa de insidioso en un tono fuerte: "Houdini parlamentario cero; es más, el martes estuve en el Senado, cero". Las repeticiones: "le diré... le diré... Finalmente, le diré algo más...". Repite, cierra y al estar en última posición tiene más fuerza.

En este segundo intercambio la confrontación es clara, y los actos de habla se cumplen de forma directa: acusación y rechazo a la misma.

\section{CONCLUSIÓN}

Las preguntas orales constituyen un tipo de texto especial, ya que está limitado en el tiempo, en la temática y en la estructura interactiva. En español consta de dos intercambios, con función informativa y argumentativa diferentes. Generalmente el primer intercambio es conocido y previsible. Su función es macroestructural: abrir la posibilidad de la interacción, es decir, de mantener una relación directa con el representante del gobierno. En el segundo intercambio encontramos el verdadero acto de habla, que suele ser una crítica al gobierno y una serie de exigencias. Por tanto, en el primero los actos de habla que aparecen actúan de forma indirecta, ya que la intención del hablante no está en lo dicho, sino en lo inferido.

Una técnica usada, sobre todo por parte del gobierno, es la evasión. Este tiende a responder de forma correcta, pero no muy directa. En la 4a intervención el tono es más fuerte y directo, y suele llegar a devolver la acusación al grupo de la oposición.

Los actos de habla realizados en las cuatro intervenciones son, pues:

1: ataque, con formas indirectas que usan generalmente la interrogación, ajustándose a lo exigido por el tipo textual y produciendo el intercambio

2: respuesta: directa o evasiva

3: ataque frontal, directo, acusación

4: evasión o defensa con ataque.

Las preguntas actúan de tres formas: a) como apertura textual, b) con valor directo, como petición de información, c) como estrategia indirecta de acusación y crítica. 
En estos intercambios hay un alto grado de descortesía, de enfrentamiento directo, que puede llegar a ser más interesante en el caso de diferencia de sexo entre los intervinientes. La limitación de espacio de este artículo nos impide tratarlo aquí, por lo que será objeto de otro trabajo.

\section{REFERENCIAS BIBLIOGRÁFICAS}

BAYLEy, P. (2004). "The whys and wherefores of analysing parliamentary discourse". P.Bayley (ed.), 1-44.

-, (2004, ed.). Cross Cultural Perspectives on Parliamentary Discourse. Amsterdam, John Benjamins.

Borthwick, R.L., 1993. "On the floor of the house". Parliamentary Questions, M.Franklin-P.Norton (eds.). Oxford, Oxford University Press, 73-103.

Briz, A.- VAlesco (2003). "Un sistema de unidades para el estudio del lenguaje coloquial". Oralia 6, 7-61.

Bull, P. y MaYer, K. (1993). "How not to answer questions in political interviews". Political Psychology 14 (4), 651-666.

Bull, P. (1994). "On identifying questions, replies and non-replies in political interviews". Journal of Language and Social Psychology 13 (2), 115-131.

-, (2003). The Microanalysis of Political Communication: Claptrap and Ambiguity. London, Routledge.

Burguera, J. (2010). Gramática y pragmática de la interrogación retórica en español. Una aplicación al debate parlamentario, Univ. Barcelona.

Chilton, P., (2002, ed). Politics as text and talk. Analytic approaches to political discourse. Philadelphia, J.Benjamins.

-, (2004). Analysing Political Discourse. London, Routledge.

Chilton, P. y Schäffner, C. (2002) "Introduction: Themes and principles in the analysis of political discourse", en P.Chilton (ed), 1-44.

Dillon, J. (1990). The Practice of Questioning. London, Routledge.

Emmertsen, S. (2007): "Interviewers' challenging questions in British debate interviews". Journal of Pragmatics 39 (2007) 570-591

Fuentes Rodríguez, C. (2000). Lingüística Pragmática y Análisis del discurso. Madrid, Arco Libros.

-, (2006). "Operadores de intensificación del adjetivo: los cuantificadores escalares". Anuario de Estudios Filológicos, XXIX, 35-53.

-, (2009a). "Parliamentary (im)politeness and argumentative force: "decirles, señorías, que...(to say, sirs, to you, that...)",.Actas del I Congreso Internacional de Estrategias del Discurso Politico/Proceedings of the I International Conference on Political Discourse Strategies, G. Álvarez Benito, G. Fernández Díaz- I. Iñigo (eds.), Sevilla, Mergablum, 63-80.

—, (2009b). "El debate entre Zapatero y_Rajoy: estudio textual e interactivo". Tonos digital 18, www.tonosdigital.com

—, (2009c). Diccionario de conectores y operadores del español. Madrid, Arco Libros. 
—,(en prensa a). "El debate Zapatero/Rajoy: estudio argumentativo", Estudios Críticos sobre la Comunicación, 1.

—, (en prensa b). "La aserción parlamentaria: de la modalidad al metadiscurso", Oralia, 2010, e.p.

Fuentes Rodríguez, C. y E. Alcaide (2002). Mecanismos lingüísticos de la persuasión. Madrid, Arco Libros.

HarRIs, S. (1991). "Evasive action: how politicians respond to questions in political interviews". Broadcast Talk, P.Scannell (ed.), London, Sage, 76-99.

—, (2001). "Being politically impolite: extending politeness theory to adversarial political discourse". Discourse and Society 12 (4), 451-472.

Heritage, J. (2002). "The limits of questioning: negative interrogatives and hostile question content". Journal of Pragmatics 34 (10-11), 1427-1446.

—, (2003). "Designing questions and setting agendas in the news interview". Studies in Language and Social Interaction, P.Glenn et al. (eds.) Mahwah, NJ., Erlbaum.

Ilie, C. (1994). What else can I tell you? A Pragmatic Study of English Rhetorical Questions as Discursive and Argumentative Acts, Stockholm, Almqvist \&Wiksell International.

—, (2003). "Parenthetically speaking: Parliamentary parentheticals as rhetorical strategies". Dialogue Analysis 2000: Selected Papers from the 10th LADA Anniversary Conference, M.Bondi-S.Stati (eds.), Tübingen, Niemeyer, 253-264.

-, (2004). "Insulting as (un)parliamentary practice in the British and Swedish parliaments: a rhetoric approach". Bayley, P. (Ed.), 45-86.

Pérez de Ayala, S. (2001). "FTAs and Erskine May: Conflicting needs? -Politeness in Question Time". Journal of Pragmatics 33, 143-169

RASIAH, P. (2010). "A framework for the systematic analysis of evasion in parliamentary discourse", Journal of Pragmatics 42. 664-680.

VAN Dijk, T.A. (2004): “Text and context of parliamentary debates”, en Bayley, P. (ed.), 339-372.

Wilson, J. (1990). Politically Speaking: The Pragmatic Analysis of Political Language. Oxford, Basil Blackwell. 